\title{
Capacity Evaluation of AC/DC Hybrid Micro-grid-Distributed Generation Considering V2G
}

\author{
Xuan Gong ${ }^{1} \mathbb{D} \cdot$ Wenyi $\mathrm{Li}^{2}$
}

Received: 18 June 2020 / Revised: 20 October 2020 / Accepted: 15 November 2020 / Published online: 7 January 2021

(c) The Author(s) 2020

\begin{abstract}
The increasing number of DC loads, such as electric vehicles (EVs), has resulted in micro-grid undergoing difficulty in satisfying the various demands of such loads. The study develops a multi-objective capacity optimization allocation model for hybrid micro-grid on the bases of users' satisfaction and the orderly charging/discharging of EVs. The proposed model aims to reduce the cost of the capacity allocation of AC/DC hybrid micro-grid and improve users' satisfaction. Particle swarm optimization algorithm is used to address the capacity optimization of hybrid micro-grid in EVs across scenarios. This study verified the rationality and effectiveness of the proposed capacity optimization model by comparing and analyzing the influence of capacity optimization on the orderly/disorderly charging/discharging of EVs and users' satisfaction.
\end{abstract}

Keywords Electric vehicles $\cdot$ Micro-grid $\cdot$ Capacity optimization $\cdot$ Users' satisfaction

\section{Introduction}

The increase in EVs and other DC loads has resulted in difficulty in meeting the demands for load diversity in and economy of AC micro-grid system. AC/DC hybrid micro-grid have gradually become one of the development paths of the micro-grid system owing to its advantages, such as access to various types of distributed power supply and economically increased DC load [1]. The optimal capacity allocation of micro-grid is a key aspect to be considered during its construction because it is closely related to economic benefits, reliability of the power supply, operation safety, and power quality of micro-grid.

At present, the research on micro-grid has been generally focused on operating and controlling AC/DC hybrid microgrid. However, the effect of access to the hybrid micro-grid on the optimal allocation capacity of EVs has been disregarded. Previous studies have investigated the capacity allocation

Wenyi Li

lwyyyll@vip.sina.com

Xuan Gong

gong_xuan_vip@163.com

1 College of Energy and Power Engineering, Inner Mongolia University of Technology, Hohhot, China

2 College of Electrical Engineering, Inner Mongolia University of Technology, Hohhot, China planning of AC/DC hybrid micro-grid under uncertain wind power, photovoltaic (PV), and load conditions [2,3].

The economy and ability of self balancing have well been considered in optimal configuration of grid connected microgrid [4-6]. And the relevant energy management strategy is proposed [7], aiming at the AC/DC micro-grid under the consideration of Optimization of power supply capacity.

The increasing number of EVs and uncertainty in terms of access quantity and time remain as challenges to the planning and intelligent scheduling of micro-grid. Given that energy storages mainly characterize EVs [8], reasonable planning and scheduling can reduce the number of energy storage devices and improve the economy of micro-grid on the basis of satisfying users' normal transportation needs.

Although an optimal dispatching scheme for the access of EVs to micro-grid under the intelligent mode has been proposed [9]; the life cycle of each distributed generation in the micro-grid is neglected. The characteristics of the mobile energy storage of EVs have indicated that the engineering field has quantified the energy storage allocation capacity of micro-grid in relation to EVs [10]. In addition, the capacity allocation of a wind-solar complementary system for EV charging stations has been optimized and analyzed in a timely manner [11]. To reduce the cost of optimal allocation and load fluctuation, a multi-objective programming model of AC/DC hybrid micro-grid with the orderly charging of EVs under comprehensive constraints was established. In 
addition, the optimal capacity allocation of AC/DC hybrid micro-grid was explored [12]. The existing research on the optimal capacity allocation of micro-grid that simplifies EVs as controllable loads has mainly focused on the optimal capacity allocation of micro-grid caused by the orderly charging of EVs. At present, in the disordered charging mode without external interference, the daily charging load curve of EVs based on the travel habits and life rules of vehicle users is consistent with the load change of micro-grid [13], which increases the energy storage capacity configuration of micro-grid and increases the burden of micro-grid operation. However, only a few studies have been conducted on the effect of the orderly discharging of EVs and users' satisfaction brought about by different charging and discharging modes on the capacity allocation of hybrid micro-grid.

Therefore, this study presents the capacity optimization of hybrid micro-grid in view of the $\mathrm{PV} /$ wind/storage hybrid $\mathrm{AC} / \mathrm{DC}$ micro-grid and given the EV ordered charging/discharging and users' satisfaction. The capacity optimization model of hybrid micro-grid is established on the basis of orderly charging/discharging of EVs and users' satisfaction. The allocation program of the power supply capacity can be derived from different scenarios through the particle swarm optimization algorithm. By comparing different modes of charging/discharging EVs, this study analyzes the influence of AC/DC hybrid micro-grid on different charging/discharging modes and user satisfaction.

\section{Ordered Discharge Model of EVs}

This research focuses on the effects of the orderly charging/ discharging of EVs on the optimal configuration of AC/DC hybrid micro-grid. Private EVs can be used as typical mobile energy storage device sowing to the short daily driving distances and long queues in charging piles.

\subsection{Effective Discharge Duration}

EVs are not constantly involved in charging/discharging while connected to charging piles, and a certain initial charge is required to participate in orderly discharging [14]. The starting charge of EVs is dependent on daily mileage and travel time. The probability density function $\mathrm{f}_{\mathrm{L}_{\mathrm{D}}}(\mathrm{x})$ for the daily travel of EVs can be calculated as follows.

$f_{L_{D}}(x)=\frac{1}{\sqrt{2 \pi} x \sigma_{D}} \exp \left[-\frac{\left(\ln x-\mu_{D}\right)^{2}}{2 \sigma_{D}^{2}}\right]$,

where $\mathrm{x}$ denotes the daily mileage, and $\mu_{\mathrm{D}}$ is the expected daily driving mileage, and $\sigma_{\mathrm{D}}$ refers to the standard deviation of daily mileage. The investigation of the US Department of Transportation 8 indicates that $\mu_{\mathrm{D}}$ and $\sigma_{\mathrm{D}}$ are evaluated at 3.2 and 0.88 , respectively, whereas $x$ ranges from 0 to 200 .

$\mathrm{T}_{\mathrm{s}}$ refers to the daily driving time of EVs, the probability density function of which can be calculated using Formula (2) as follows.

$f_{T_{d}}(t)=\frac{1}{\sqrt{2 \pi} t \sigma_{D}} \exp \left[-\frac{\left(\ln t+\ln V_{s}-\mu_{D}\right)^{2}}{2 \sigma_{D}^{2}}\right]$,

where $V_{s}$ is the average speed and $t$ pertains to travel duration. In addition, $\mathrm{t}$ should be within specific limits as follows:

$0<t \leq \frac{200}{V_{s}}$,

Probability function $\mathrm{f}_{\mathrm{T}_{\mathrm{d}}}(\mathrm{x})$ of the effective discharge duration of $E V T_{d}$ can be calculated using Formula (4) as follows.

$$
\begin{aligned}
f_{T_{s}}(t)= & \frac{P_{d}}{\sqrt{2 \pi}\left(0.8 C_{b}-t \times P_{d}\right) \sigma_{D}} \\
& \times \exp \left[-\frac{\left.\left[\ln 0.8 C_{b}-t \times P_{d}\right)-\ln 0.15_{s}-\mu_{D}\right]^{2}}{2 \sigma_{D}^{2}}\right],
\end{aligned}
$$

where the selection of $\mu_{D}$ and $\sigma_{D}$ can refer to Formula (1) and $t$ is the discharge time of EVs to micro-grid. The selection oft should be within specific limits as follows.

$\frac{0.8 C_{b}-30}{P_{d}} \leq t<\frac{0.8 C_{b}}{P_{d}}$.

\subsection{Time of Discharge}

In terms of the orderly charging of EVs, starting time refers to the peak and valley price periods of the power supply system. When the discharge time is less than the peak price period based on retaining daily driving power consumption, users can start discharging any time within the peak price range that meets the full discharge time. When the time consumption of discharge is more than the peak price time interval, the start time of discharging will be selected at the initiation time of peak price. The time period beyond the peak price interval will be calculated according to the level or valley price time period. Formula (6) can be used to calculate the ordered discharge time $\mathrm{t}_{\mathrm{f}}$ as follows.

$t_{f}=\left(\begin{array}{cc}t_{p s}+k_{c} \times\left(t_{p e}-T_{d}-t_{p s}\right), \quad 0 \leq T_{d} \leq\left(t_{p e}-t_{p s}\right) \\ t_{p s} & T_{d c}>\left(t_{p e}-t_{p s}\right)\end{array}\right.$,

where $T_{d}$ denotes the length of time required, $t_{p s}$ is the start time of EVs in the peak period of electricity discharge, $t_{\mathrm{pe}}$ refers to the completion time of discharge, and $\mathrm{k}_{\mathrm{c}}$ is a coefficient with values ranging from 0 to 1 . 


\section{Optimal Capacity Allocation Model for AC/ DC Hybrid Micro-grid Containing EVs}

Various distributed generators and energy storage devices are connected to DC and AC buses, respectively, during the normal operation of hybrid micro-grid, thereby reducing power loss compared with traditional AC micro-grid. Moreover, the economy of hybrid micro-grid and user satisfaction should be improved, and power loss caused by power exchange between the AC and DC sides of hybrid micro-grid should also be reduced during the optimal capacity allocation of AC/DC hybrid micro-grid.

\subsection{Objective Function}

\subsubsection{Economic Cost}

The economic costs of AC/DC hybrid micro-grid comprise the costs of the initial equipment investment, operation and maintenance, charging/discharging of EVs, power interaction cost between micro-grid and power distribution networks, and residual cost of the power system after the entire life cycle. Life cycle cost is typically expressed as in Formula (7).

$C_{\text {Total }}=C_{s}+C_{y}+C_{d}+C_{j}-C_{r}$

where $\mathrm{C}_{\text {Total }}$ is the economic cost of the total life cycle of hybrid micro-grid, $\mathrm{C}_{\mathrm{s}}$ is the initial equipment cost of microgrid, $\mathrm{C}_{\mathrm{y}}$ denotes the operation and maintenance cost of micro-grid, $\mathrm{C}_{\mathrm{d}}$ pertains to the charging/discharging costs of $\mathrm{EVs}, \mathrm{C}_{\mathrm{j}}$ is the cost of electric power interaction between hybrid micro-grid and distribution power network, and $\mathrm{C}_{\mathrm{r}}$ is the residual value of the hybrid micro-grid system after the total life cycle.

3.1.1.1 Cost of the Initial Equipment Investment The cost of the initial equipment investment $\mathrm{C}_{\mathrm{s}}$ comprises the cost of the initial operation of various distributed generators and converters. Compared with centralized power generation, the high cost of initial investment has become the main constraint factor. However, the constraints are expected to be alleviated with the development of science and technology. The initial investment cost of hybrid micro-grid equipment is calculated using the equivalent annual method [15], which is shown as in Formula (8) as follows.

$C_{s}=\sum_{i=1}^{N} K_{i} C_{i} \frac{r(1+r)^{Y_{i}}}{(1+r)^{Y_{i}}-1}$,

where $\mathrm{N}$ is the species number of power sources in the hybrid micro-grid systems. $\mathrm{K}_{\mathrm{i}}$ denotes the number of i-type distributed power supply, and $\mathrm{C}_{\mathrm{i}}$ refers to the cost of the $\mathrm{i}$ -type distributed power supply investment in the initial stage of hybrid micro-grid construction. $\mathrm{Y}_{\mathrm{i}}$ stands for the service life of the i-type distributed power generation, and $r$ is the discount rate, which is takes a value of 8.10 . In this study, wind power, PV, and storage battery are selected for hybrid micro-grid distributed generation.

\subsubsection{Operation and Maintenance Cost of Hybrid} Micro-grid The entire lifecycle of hybrid micro-grid is typically planned for 20 years. Apart from storage battery, which requires replacement within the 20 years because of frequent charging/discharging, the life cycle of other power sources is beyond the planning period. The operation cost of micro-grid is mainly related to transmission power, such as the generation operation cost of distributed generation and operation cost of storage battery, which is shown in Formula (9) as follows.

$C_{y}=C_{z}+\sum_{i=1}^{N} \sum_{j=1}^{K_{i}} \sum_{t=1}^{T} k_{i} P_{i b t}$,

where $C_{z}$ is the replacement cost of batteries, and $T$ is the total operation time of hybrid micro-grid during the life cycle. The $k_{i}$ represents the operating factor of the $i$-type hybrid micro-grid equipment, and $P_{i b t}$ is the output power value of unit $b$ of class $i$ equipment of the system at time $t$.

3.1.1.3 Interaction Cost of the Hybrid Micro-grid and Power Distribution Networks The interaction cost of the hybrid micro-grid and power distribution networks comprises the cost of purchasing electricity from power distribution networks and revenue from selling electricity to power distribution networks, which is shown in Formula (10) as follows.

$C_{j}=\sum_{t=1}^{T}\left(k_{b t} P_{b t}-k_{s t} P_{s t}\right)$,

where $P_{b t}$ and $P_{s t}$ refer to the power of hybrid micro-grid that purchase electricity from power distribution networks and sell electricity to power distribution networks, respectively, at time $t . k_{b t}$ and $k_{s t}$ denote the prices of purchasing and selling electricity from power distribution networks, respectively, at time $t$.

3.1.1.4 Cost of EV Ordered Charging/Discharging The charging/discharging time of EVs can be adjusted according to the peak and valley prices. Charging during valley price scan lower the cost of charging, whereas discharging during peak period scan make maximize revenue. The cost of charging/discharging can be calculated using Formula (11) as follows. 
$C_{d}=\sum_{i=1}^{n} \sum_{t=1}^{T}\left(k_{f t} P_{f t, i}-k_{c t} P_{c t, i}\right)+C_{b}$

where $n$ is the number of EVs participating intheorderly charging/discharging in micro-grid; $k_{f t}$ and $k_{c t}$ are the electrovalence values of the orderly discharging/charging of EVs at time $t$, respectively [16]; $P_{f t, i}$ and $P_{c t, i}$ pertain to the power of $i$ EV discharging to hybrid micro-grid and charging from micro-grid at time $t$, respectively; and $C_{b}$ denotes the subsidy of the participating EV users, who will be subsidized accordingly for battery consumption and for participating in repeated and orderly charging/discharging, which reduces service life.

$k_{f t}=\left\{\begin{array}{ll}k_{p} & t_{p s} \leq t \leq t_{p e} \\ k_{c} & t_{c s} \leq t \leq t_{c e} \\ k_{n} & \text { other }\end{array}\right.$,

where $k_{c t}$ refers to the charging price, which is similar to $k_{f t}$ and can be calculated according to charging time located in the different time zones of the peak and valley electricity prices. User subsidy $C_{b}$ can be calculated using Formula (13) as follows.

$C_{b}=p k_{t} T_{d}$

where $p$ is the subsidy coefficient and takes a value of 0.4 in the present study [17] $k_{t}$ is the average electricity price within the discharge period, and $T_{d}$ refers to the discharge duration.

\subsubsection{Loss of Converter Transformers}

In contrast to traditional AC micro-grid, distributed generators and loads are connected to the $\mathrm{AC}$ and DC buses of $\mathrm{AC} /$ DC hybrid micro-grid, respectively. PV, energy storage, and DC loads, such as EVs, are connected to DC buses. By contrast, wind power and AC loads are connected to AC buses, thereby reducing converter losses. The loss of converter transformers $P_{l s}$ is calculated using Formula (14) as follows.

$P_{l s}=(1-\sigma) P_{t r}$,

where $P_{t r}$ is the converter power between different buses in hybrid micro-grid and $\sigma$ stands for converter efficiency.

\subsubsection{Satisfaction of EV Users}

Vehicle usage habits will be optimized and adjusted in an orderly manner during the optimization of the allocation of load resources, which will reduce users' experience to a certain extent. User satisfaction reflects the quality of the vehicle users' experience, which is quantified by the cost of charging/discharging and difference between charging/ discharging schemes, as shown in Formula (15).

$U_{s a t}=\sum_{i=1}^{n} \sum_{t=1}^{T}\left(k_{t} P_{t}-k_{c t} P_{c t, i}\right)-C_{j}$,

Although the difference between orderly and disorderly charging/discharging time distribution is reduced (i.e., the time selection of orderly charging/discharging is similar to the users' original habits), users' satisfaction will be increased. By contrast, user' satisfaction will be reduced when the time distribution of orderly charging/discharging deviates from the time probability distribution of disorderly charging/discharging.

\subsection{Operation Constraint Condition of the AC/DC Hybrid Micro-grid}

\subsubsection{Output Power Constraints of the Distributed Generation}

The output power constraints of wind power and PV are shown in Formula (16) as follows.

$\left\{\begin{array}{l}0 \leq P_{w t} \leq P_{w t m} \\ 0 \leq P_{p v} \leq P_{p v m}\end{array}\right.$

where $P_{w t m}$ and $P_{p v m}$ are the maximum output power of wind power and $\mathrm{PV}$, respectively.

\subsubsection{Constraints of Storage Battery}

The capacity and operating constraints of storage battery are shown in Formula (17) as follows.

$\left\{\begin{array}{l}S O C_{\text {min }} \leq S O C \leq S O C_{\text {max }} \\ P_{\text {in }} \leq P_{c \max } \\ P_{\text {out }} \leq P_{d \text { max }}\end{array}\right.$

where $S O V_{\min }$ and $S O V_{\max }$ are the maximum and minimum limits, respectively, of the charge capacity of batteries; and $P_{c \max }$ and $P_{d \max }$ denote the maximum limit of battery charging/discharging power, respectively.

\subsubsection{Power Constraints of EVs}

$\left\{\begin{array}{l}S_{E V \min } \leq S_{E V} \leq S_{E V \max } \\ 0 \leq P_{E V c} \leq P_{E V c \max } \\ 0 \leq P_{E V d} \leq P_{E V d \max }\end{array}\right.$, 
Table 1 Economic parameters of hybrid micro-grid systems

\begin{tabular}{lllll}
\hline Distributed generation & Specification parameters & Investment cost (RMB) & $\begin{array}{l}\text { Maintenance } \\
\text { cost for operation } \\
\text { (RMB) }\end{array}$ & $\begin{array}{l}\text { Service } \\
\text { life } \\
\text { (years) }\end{array}$ \\
\hline Wind power & $30 \mathrm{~kW}$ & $10,000 / \mathrm{kW}$ & $1900 /$ set/year & 20 \\
PVs & $1 \mathrm{~kW}$ & $10,000 / \mathrm{kW}$ & $20 / \mathrm{kW}$ & 20 \\
Storage battery & $2 \mathrm{~V} / 1000(\mathrm{~A} \mathrm{~h})$ & $1200 / \mathrm{kWh}$ & $5 / \mathrm{set}$ & 10 \\
Converter & $1 \mathrm{~kW}$ & $2000 / \mathrm{kW}$ & 5 & 10 \\
\hline
\end{tabular}

where $S_{E V \min }$ and $S_{E V \max }$ are the minimum and maximum charge capacities, respectively, of EVs; and $P_{E V c m a x}$ and $P_{\text {EVdmax }}$ are the maximum power of charging/discharging, respectively, for EVs.

\subsubsection{Interactive Power Constraints in Power Distribution Networks}

A power distribution network will be extremely affected when interactive power between hybrid micro-grid and distribution network increase. Therefore, the power constraints on hybrid micro-grid are formulated as Formula (19) as follows.

$P_{\text {sold }} \leq P_{\text {sold } \max }$,

where $P_{\text {soldmax }}$ is the maximum power transfer from hybrid micro-grid tothedistribution network.

\section{Results and Discussion}

\subsection{Example}

This study proposes an AC/DC hybrid micro-grid capacity allocation model on the basis of an actual power grid situation in a certain area in Inner Mongolia. In particular, this research investigates the optimal capacity allocation of hybrid micro-grid with EVs [18]. An AC/DC hybrid microgrid comprises wind power, $\mathrm{PV}$, storage battery, and other distributed power sources, and loads, such as EVs and other forms. The relevant economic parameters of AC/DC hybrid micro-grid are provided in Table 1.

The light resources are illustrated in Fig. 1. The average annual wind speed in a region is approximately $6.7 \mathrm{~m} / \mathrm{s}$. The average daily irradiation intensity is approximately 4.55 $(\mathrm{kW} \mathrm{h}) /\left(\mathrm{m}^{2} \mathrm{~d}\right)$. The state of charge (SOC) of battery ranges from 0.5 to 0.95 [19, 20], and the initial SOC of storage batteries take a value of 0.8 . The maximum loads in summer and winter are approximately $390 \mathrm{~kW}$ and $300 \mathrm{~kW}$, respectively. The number of EVs is set to 300 . Table 2 presents other parameters $[21,22]$.

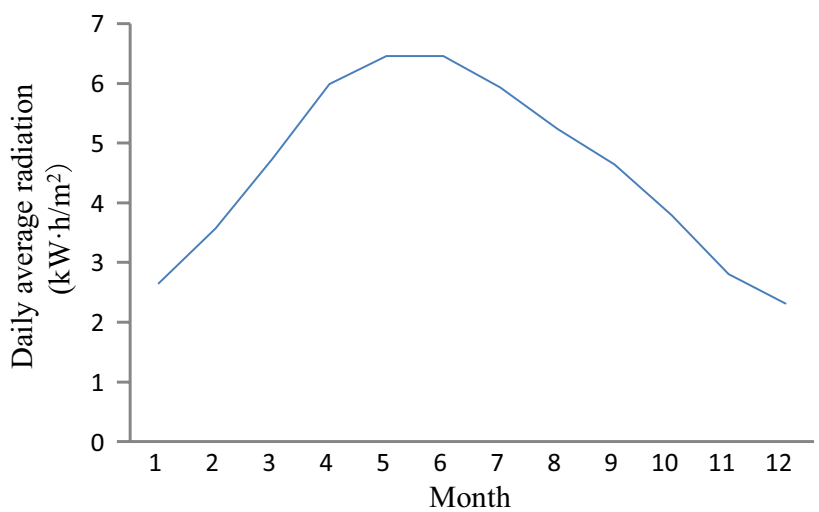

Fig. 1 Irradiance curve in certain areas

Table 2 Parameter setting of EV

\begin{tabular}{lllll}
\hline $\begin{array}{l}\text { Battery } \\
\text { capacity }(\mathrm{Cb})\end{array}$ & $\begin{array}{l}\text { Average } \\
\text { energy } \\
\text { consumption } \\
(\mathrm{W})\end{array}$ & $\begin{array}{l}\text { Charge-dis- } \\
\text { charge power } \\
(\mathrm{kW})\end{array}$ & SOC & $\begin{array}{l}\text { Charging/ } \\
\text { discharging } \\
\text { efficiency }\end{array}$ \\
\hline $40-80$ & 0.15 & $4-6$ & $20-90 \%$ & 0.92 \\
\hline
\end{tabular}

\subsection{Scenarios Analysis}

The optimal capacity allocation of AC/DC hybrid microgrid is investigated under the following scenarios: (1) disorderly charging, (2) orderly charging/discharging scenarios, and (3) satisfaction of EV users.

This study highlights the charging/discharging status of EVs within $24 \mathrm{~h}$, and typical days in the summer and winter seasons are selected. In addition, this study identifies and analyzes the influence of orderly charging/discharging of EVs on the optimal capacity allocation of hybrid microgrid. Figure 2 depicts the load curves of certain areas in the summer and winter. The maximum and second load peak occurred at $8 \mathrm{pm}$ and $1 \mathrm{pm}$, respectively, whereas the minimum load occurred at $4 \mathrm{am}$. In the summer, the gap between peak and trough loads is large with large fluctuations. By contrast, load fluctuation is relatively gentle during the winter. 


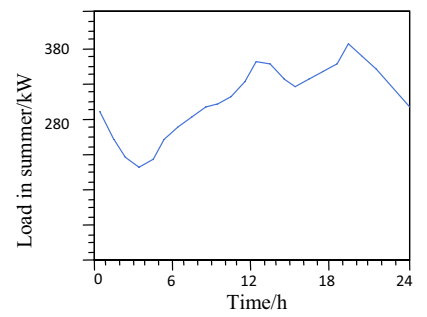

(a)

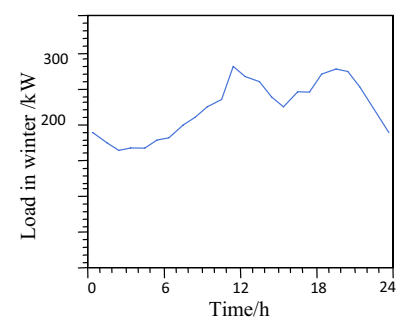

(b)
Fig. 2 Load curve of typical days in the summer and winter in certain areas

Table 3 Capacity optimization of hybrid micro-grid across scenarios

\begin{tabular}{lllll}
\hline Collocation & $\begin{array}{l}30 \mathrm{~kW} \text { wind } \\
\text { turbine/set }\end{array}$ & PV/kW & Battery/set & $\begin{array}{l}\text { Converter } \\
\text { capacity/ } \\
\mathrm{kW}\end{array}$ \\
\hline Scenario 1 & 14 & 385 & 923 & 160 \\
Scenario 2 & 14 & 279 & 680 & 230 \\
Scenario 3 & 14 & 256 & 623 & 255 \\
\hline
\end{tabular}

Table 3 presents the results of the optimal capacity allocation for hybrid micro-grid across scenarios.

\subsubsection{Optimal Capacity Configuration Analysis of Hybrid micro-grid in EV Sunder Disorderely Charging Scenario}

The optimal capacity allocation results of AC/DC hybrid micro-grid in the disorderly charging scenario are listed in scenario 1 of Table 3 . A total of 14 wind turbines, 385 KW PVs, and 923 energy storage batteries are included. During the operation life cycle of hybrid micro-grid, the initial installation cost of micro-grid can reach RMB $13,304,000$, whereas the operation and maintenance cost can reach RMB 70,100.

EVs are randomly and disorderly charged without the guidance of market time-sharing price. Figure 3 demonstrates the charging power expectation, in which the fluctuation of power expectation of EVs is evident, thereby increasing the gap between the peak and valley of the load curve.

Figure 4 shows that the peak load of a system increases in the case of disorderly charging of EVs, thereby aggravating the load fluctuation of hybrid micro-grid. The energy storage capacity should increase under circumstances where wind power and photovoltaic capacity remain unchanged, thereby increasing the economic cost.

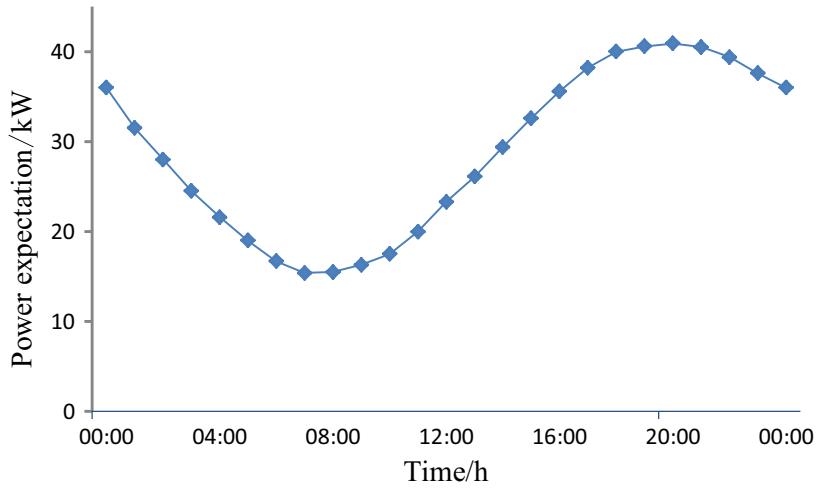

Fig. 3 Expected disorderly charging of EVs

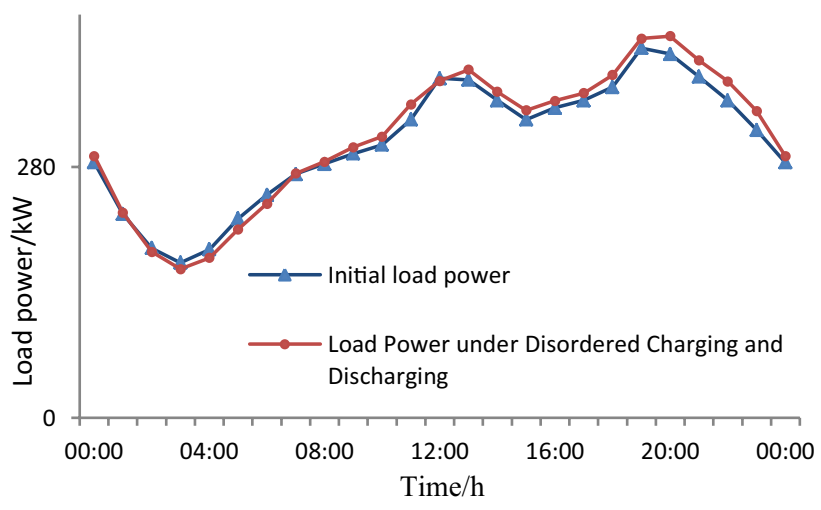

Fig. 4 Load power curve of EVs in disorderly charging mode

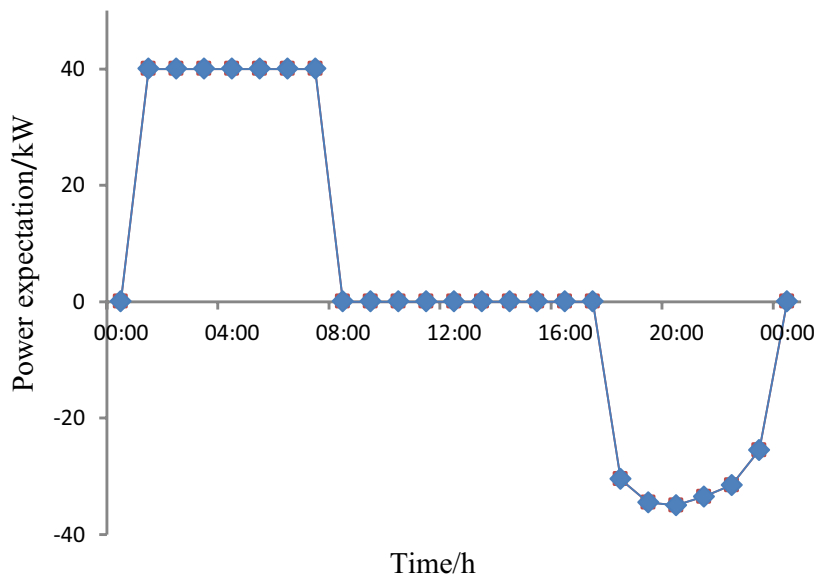

Fig. 5 Expectation of EV charging in orderly mode

\subsubsection{Optimal Capacity Configuration Analysis of Hybrid Micro-grid in Orderly Charging/Discharging Scenario of EVs}

Figure 5 presents the power expectation of EVs in the case of sequential charging/discharging. 
Table 4 Peak-valley time-of-use of electricity prices

\begin{tabular}{lll}
\hline Time & Paying price & Sale price \\
\hline Peak price period & 1.05 & 0.73 \\
Valley price period & 0.41 & 0.27 \\
Ordinary period & 0.81 & 0.35 \\
\hline
\end{tabular}

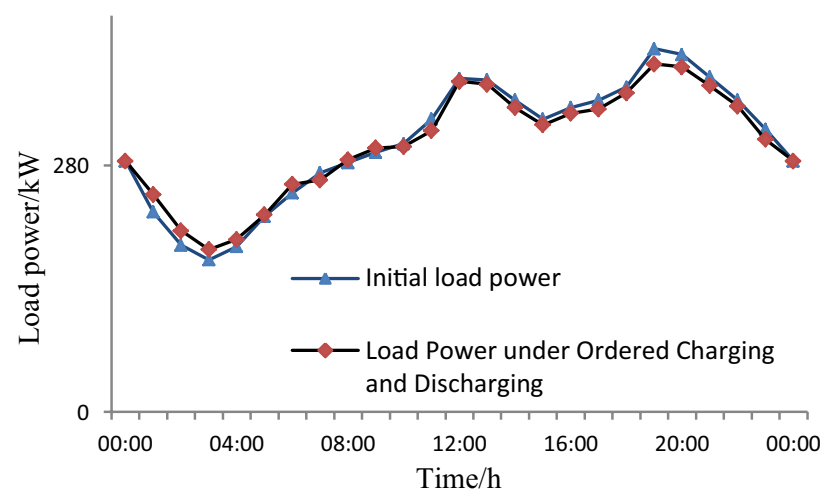

Fig. 6 Expectation of EV charging in the orderly mode

In the orderly charging scenario, EV owners can be guided in orderly charging according to the peak and valley price periods and time required for charging. The load can be transferred by changing the original disorderly charging mode of EVs. Table 4 lists the peak-valley time-of-use electricity prices.

In particular, the peak price period ranges from 11 am to $2 \mathrm{pm}$ and from 7 to $11 \mathrm{pm}$, whereas the valley price period ranges from 12 to $7 \mathrm{am}$, and the remainder is considered a normal price period.

Figure 6 shows that the maximum load is reduced by $11 \%$, as guided by peak and valley electricity prices, which play the role of filling valleys and cutting peaks during the peak and valley price periods. In the orderly charging/discharging scenario of EVs, the optimal capacity configuration of hybrid micro-grid is shown in scenario 2 of Table 3. A total of 14 wind turbines, 279-KW PVs , and 680 energy storage batteries are included, and the installation cost of hybrid micro-grid can reach RMB 11.74 million. The operation cost is RMB 0.068 million, which indicates that the economic cost of hybrid micro-grid in the orderly charging/discharging scenario is reduced by $15 \%$ compared with the disorderly charging/discharging scenario of EVs.

\subsubsection{Capacity Optimization Analysis of Hybrid Micro-grid Considering Satisfaction of Elecrivc Vehicle Users}

A certain proportion of EV owners are encouraged to implement orderly charging/discharging combined with peak and valley electricity prices to promote their prices in the power market. However, a percentage of car owners maintain the original disordered charging/discharging mode. The enthusiasm of EV owners to participate in orderly charging can be enhanced by improving users' satisfaction of EVs. This endeavor can increase the proportion of users participating in orderly charging/discharging and extend the effect of EV mobile energy storage on peak load shifting.

Scenario 3 in Table 3 depicts the optimal capacity allocation of hybrid micro-grid that considers the satisfaction of EV owners based on orderly charging/discharging of EVs. A total of 14 wind turbines, 256-KW PVs, and 623 energy storage batteries are included, and the installation and operation costs of hybrid micro-grid can reach RMB 10.73 and 0.065 million, respectively. The AC and DC bus power of hybrid micro-grid and converter capacity should be increased to meet the peak load supply because of the reduction in distributed power supply capacity. The economic cost of hybrid micro-grid under the user satisfaction scenario is reduced by $18.3 \%$ compared with the disorderly charging/discharging of EVs.

Figure 7 presents the orderly charging/discharging in the winter and summer, respectively. The number of EV users participating in orderly charging/discharging increases with the improvement of user satisfaction.

The economy of capacity allocation of hybrid micro-grid is improved with the reduction in peak load and smoothing of the load curve. By contrast, the economy of the capacity allocation of hybrid micro-grid will be decreased in the orderly charging/discharging of EV sowing to the low level of satisfaction of users and less number of users participating in orderly charging/discharging.

\section{Conclusion}

This study investigates the multi-objective capacity optimal allocation of AC/DC hybrid micro-grid for EVs under three scenarios. The influence of the different charging/discharging modes of EVs on the optimal capacity allocation of micro-grid is verified, and the influence of user satisfaction on the optimal capacity allocation of hybrid micro-grid is further considered. The main contributions of this research are as follows.

(1) The peak load of hybrid micro-grid can be reduced, and the load curve can be alleviated through orderly charging/discharging of EVs. Compared with disordered charging/discharging, the installation and operation costs of the distributed generation of hybrid micro-grid are reduced, and the economy of capacity allocation of $\mathrm{AC} / \mathrm{DC}$ hybrid micro-grid is increased.

(2) The number of EV users participating in orderly charging/discharging is increased with the improvement in 


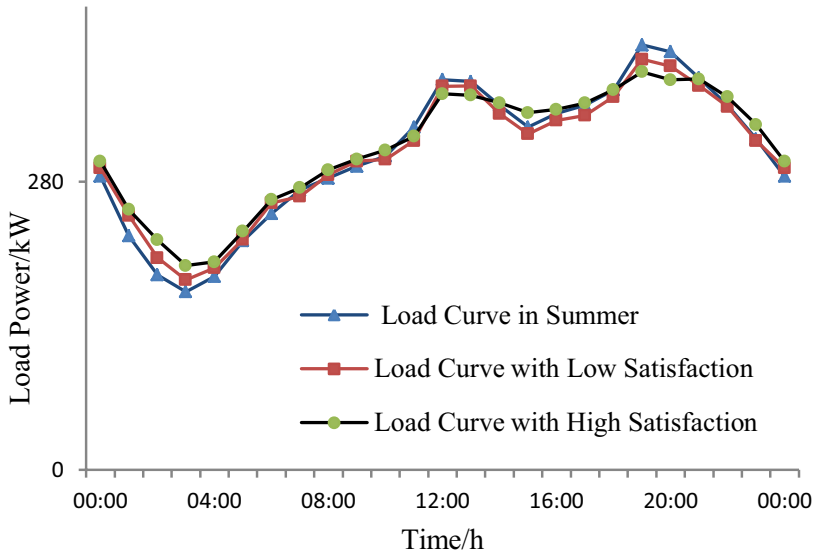

(a)

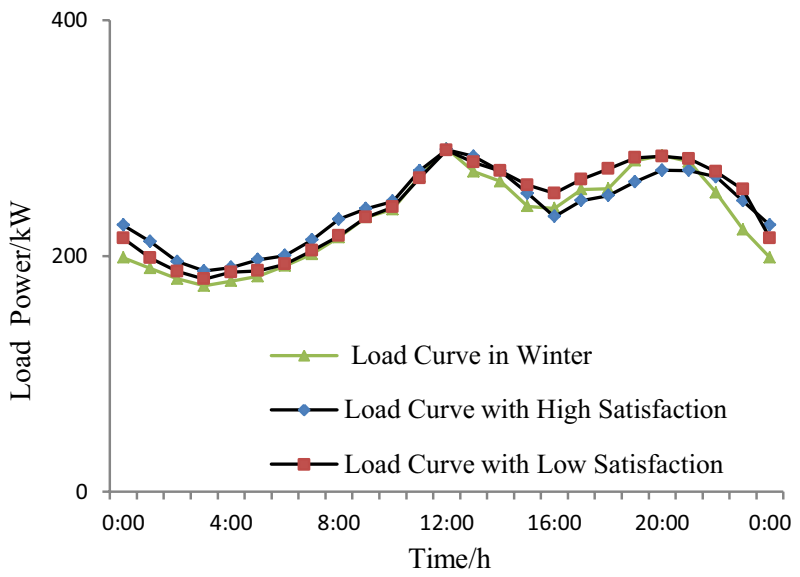

(b)

Fig. 7 Load power curve in the summer and winter according to user satisfaction

users' satisfaction. The economy of capacity allocation of hybrid micro-grid is improved, and the effect of cutting peak and smoothing curve on orderly charging/ discharging of EVs is notable.

This study considered the orderly charging/discharging of EVs and user satisfaction. However, future studies can explore the effects of the capacity allocation of hybrid micro-grid on EVs, particularly given the demand side responses.

Acknowledgements This research has been supported by The Wind and Solar Energy Utilization Technology Key Labs Co-constructed by Province and the Ministry of Education Fund (No. 201611) and The Inner Mongolia Scientific Research Innovation Fund (No. B2018111922Z).

Open Access This article is licensed under a Creative Commons Attribution 4.0 International License, which permits use, sharing, adaptation, distribution and reproduction in any medium or format, as long as you give appropriate credit to the original author(s) and the source, provide a link to the Creative Commons licence, and indicate if changes were made. The images or other third party material in this article are included in the article's Creative Commons licence, unless indicated otherwise in a credit line to the material. If material is not included in the article's Creative Commons licence and your intended use is not permitted by statutory regulation or exceeds the permitted use, you will need to obtain permission directly from the copyright holder. To view a copy of this licence, visit http://creativecommons.org/licenses/by/4.0/.

\section{References}

1. Ma T, Cintuglu MH (2017) Control of hybrid AC/DC microgrid involving storage, renewable energy and pulse loads. IEEE Trans Ind Appl 53(1):567-575

2. Babolip T, Shahparasti M, Mogh-Addam MP et al (2014) Energy management and operation modeling of hybrid AC/DC microgrid. IET Gener Transm Distrib 8(10):1700-1711

3. Zhao B, Wang X, Zhang X et al (2018) Two-layer method of microgrid optimal sizing considering demand-side response and uncertainties. Trans China Electro Tech Soc 33(14):3284-3295

4. Akram U, Khalid M, Shafiq S (2018) Optimal sizing of a wind/ solar/battery hybrid grid-connected microgrid system. IET Renew Power Gener 12(1):72-80

5. Nguyen-Hong N, Nguyen-Duc H, Nakanishi Y (2018) Optimal sizing of energy storage devices in isolated wind-diesel systems considering load growth uncertainty. IEEE Trans Ind Appl 54(3):1983-1991

6. Bai K, Gu J, Peng H et al (2018) Optimal allocation for multienergy complementary microgrid based on scenario generation of wind power and photovoltaic output. Autom Electr Power Syst 42(15):133-141

7. Wang X, Zhao B, Wu H et al (2016) Optimal sizing analysis of grid-connected hybrid AC-DC microgrid. Autom Electr Power Syst 40(13):55-62

8. Cheng S, Wang X, Feng Y (2018) Decent realized optimization of ordered charging scheduling in electric vehicle charging station. Autom Electr Power Syst 42(1):39-46. https://doi.org/10.7500/ AEPS20170630001

9. Su S, Jiang X (2015) Optimal energy management for microgrids considering electric vehicles and photovoltaic-energy storage. Autom Electr Power Syst 39(9):164-171. https://doi.org/10.7500/ AEPS20140115012

10. Zhang M, Xie Q et al (2015) Optimal sizing of energy storage for microgrids considering energy management of electric vehicles. Proc CSEE 35(18):4663-4673

11. Zhang Y, Liu N et al (2013) Optimum sizing of a stand-alone hybrid PV/wind generation system integrated with electric vehicle charging stations. Power Syst Prot Control 15:126-134

12. Ming DING, Shengliang SHI, Hao PAN (2018) Planning of AC/ DC hybrid microgrid with integration of electric vehicles charging load. Autom Electr Power Syst 42(01):32-38. https://doi. org/10.7500/AEPS20170527003

13. Li-ting TIAN, Shuang-long SHI, Zhuo JIA (2010) A statistical model for charging power demand of electric vehicles. Power Syst Technol 34(11):126-130

14. Taylor MJ, Alexander A (2009) Evaluation of the impact of plugin electric vehicle loading on distribution system operations. IEEE power and energy society general meeting. IEEE, Calgary, pp 1-6

15. Bo Z (2015) Key technologies and applications of microgrids optimal allocation. Science Press, Beijing

16. Xianggang PENG, Lixiang LIN, Yi LIU et al (2015) Multiobjective optimal allocation of distributed generation considering uncertainties of plug-in electric vehicles and renewable energy source. Power Syst Technol 39(8):2188-2194 
17. Liu C, Chau KT et al (2013) Opportunities and challenges of vehicle-to- home, vehicle- to- vehicle, and vehicle-to-grid technologies. Proc IEEE 101(11):2409-2427

18. Nikhil G, Wang L (2012) A demand side management based simulation platform incorporating heuristic optimization for management of household appliances. Int J Electr Power Energy Syst 43(1):185-193

19. Xiangjin W, Bo Z (2016) Optimal sizing analysis of grid-connected hybrid AC/DC microgrid. Autom Electr Power Syst 40(13):55-62. https://doi.org/10.7500/AEPS20151105005

20. Bo ZHAO, Kankan BAO (2015) Optimal sizing for grid-connected PV-and-storage microgrid considering demand response. Proc CSEE 35(21):5465-5474

21. Gaoping BAI (2011) Research on the adaptability of large-scale electric vehicle charging (discharging)station and the grid. Beijing Jiaotong University, Beijing

22. Su H, Liang Z (2015) Orderly charging control based on peak-valley electricity tariffs for household electric vehicles of residential quarter. Electr Power Autom Equip 35(6): 17-22

Publisher's Note Springer Nature remains neutral with regard to jurisdictional claims in published maps and institutional affiliations.

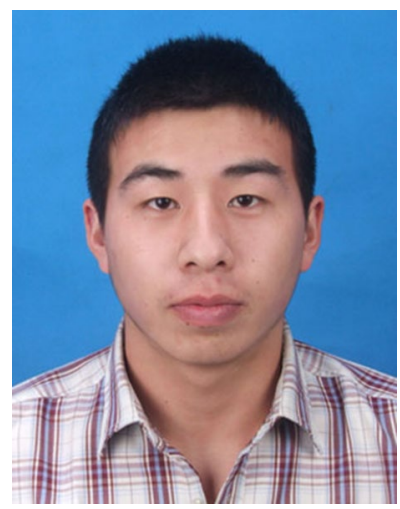

Xuan Gong male, born in 1991, Ph.D student. Main research direction is the optimal allocation of microgrid capacity.

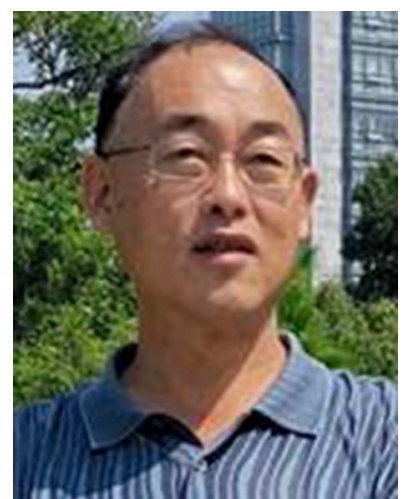

Wenyi Li male, born in 1963 , Professor and Ph.D supervisor. The corresponding author. Main research direction is the renewable energy power generation and the reliability evaluation, etc. 